\title{
An anthropometric study for correlation between digit ratio and demographic and psychological parameters
}

\author{
Dinanath Pujari ${ }^{1},{ }^{A}$ Ashwini $V^{2 *}$
}

${ }^{1}$ Associate Professor, Department of Anatomy, ESIC M edical College, Kalaburagi, Karnataka, INDIA. 2Professor, Department of Physiology, M. R. M edical College, Kalaburagi, Karnataka, INDIA.

Email: moukthikalaxmipublishinghouse@gmail.com

$\underline{\text { Abstract }}$

Background: The 2D:4D ratio was considered as an indicator of prenatal sex hormones mainly estrogen and testosterone. Association was reported between the psychological and demographical parameters with the ratio of digits. Aims and objectives: The study aimed to observe the correlation between ratio of digits and demographic and psychological parameters. Materials and methods: A total of fifty healthy female participants within the age group of 20-28 years were part of the study. The length of the right hand second and forth digit finger was measured as specified in the literature and the ratio of two was mentioned as 2D:4D ratio. Height and weight were measured by standard methods. Psychological parameters were measured using standard questionnaire. Results: There was negative association between the ratio of digits and depression and stress whereas positive association between the ratio of digits and anxiety. There was negative association between the ratio of digits and height and weight. Conclusion: The digit ratio has negative correlation with depression, stress, height and weight parameters and has positive correlation with the anxiety. We recommend further detailed studies in this area to understand the association of these parameters.

Key Word: Digit ratio, stress, anxiety, depression, correlation.

\section{*Address for Correspondence:}

Dr. A. Ashwini.V, Professor, Department of Physiology, M. R. Medical College, Kalaburagi, Karnataka, INDIA.

Email: moukthikalaxmipublishinghouse@gmail.com

Received Date: 20/09/2018 Revised Date: 17/10/2018 Accepted Date: 06/11/2018

\section{DOI: https://doi.org/10.26611/1001821}

\begin{tabular}{|l|l|}
\hline \multicolumn{2}{|c|}{ Access this article online } \\
\hline Quick Response Code: & Website: \\
\hline & www.medpulse.in \\
\hline
\end{tabular}

\section{INTRODUCTION}

Understanding and estimating the prenatal parameters helps to estimate the diseases to which particular individual are more prone for. One such parameter is assessment of ratio of $2^{\text {nd }}$ and $4^{\text {th }}$ finger length. It is called as $2 \mathrm{D}: 4 \mathrm{D}$ ratio, which is attracting the interest of researchers as it is being correlated with not only with anthropometric data but also with psychological and clinical parameters. Further, it was reported that males have significantly lower digit ratio than females. ${ }^{1}$ Digit ratio was reported as a measure of prenatal sex hormones mainly estrogen and testosterone. These steroid hormones play a pivot role in fetal development. ${ }^{2-5}$ There was a correlation between the anthropometric parameters, behavioral parameters with the digit ratio. ${ }^{6-8}$ The digit ratio may correlate with the cardiovascular diseases also. ${ }^{9}$ Higher ratio of digits, higher is the prevalence of development of cardiovascular diseases. There were contradictory results regarding association of the ratio of digits with the demographic parameters. Some studies reported negative association ${ }^{10}$ and some reported no correlation. ${ }^{11}$ Thecurrent study was aimed to observe the correlation between digit ratio and demographic and psychological parameters.

\section{MATERIALS AND METHODS}

Study design: Cross-sectional study

Study participants: The study included fifty healthy female participants. The following criteria were used in the selection of the participants. 
Inclusion and exclusion criteria: Healthy participants within the age group of 20-28 years and those willing to participate in study were included in the study. Those undergoing any treatment or therapy were excluded from the study.

Study setting: The present study was conducted at M.R. Medical College, Gulburga, Karnataka.

Digit ratio: The lengths of second digit and fourth digit was measured from the fingertip to the midpoint of the basal crease, on the ventral surface of the hand, using digital vernier calipers. The 2D:4D ratio is obtained by dividing these values ${ }^{12,27}$

Assessment of height and weight: Height and weight was measured by using standard methods. ${ }^{13}$

Assessment of psychological measures: The psychological parameters that is depression, anxiety and stress are recorded using the standard DASS scale $42 .{ }^{14}$

Ethical consideration: The study protocol was approved by institutional human ethical committee.

Data analysis: Data was analysed using the version of SPSS 20.0. To observe the association between the variables we have used Pearson correlation coefficient. Probability less than 0.05 considered as significant.

\section{RESULTS}

There was negative association between the ratio of digits and depression and stress whereas positive association between the ratio of digits and anxiety (table no 1). There was negative association between the ratio of digits and height and weight (table no 2).

Table 1: Association of 2D:4d ratio with depression, anxiety and stress. (Data was presented as M ean and SD).

\begin{tabular}{ccccc}
\hline Parameter & Mean \pm SD & 2D:4D ratio & $r$ & P value \\
\hline Depression & $16.22 \pm 4.71$ & & -0.3507 & 0.3548 \\
Anxiety & $13.0 \pm 4.0$ & \multirow{2}{*}{$0.97 \pm 0.1256$} & 0.2405 & 0.5330 \\
Stress & $19.0 \pm 5.75$ & & -0.1594 & 0.6821 \\
\hline
\end{tabular}

Table 2: Asso ciation of 2D:4d ratio with height and weight. (Data was presented as M ean and SD).

\begin{tabular}{lcccc}
\hline Parameter & Mean \pm SD & 2D:4D ratio & r & P value \\
\hline Height $(\mathbf{c m})$ & $162.22 \pm 13.47$ & \multirow{2}{*}{$0.97 \pm 0.1256$} & -0.5275 & 0.1444 \\
Weight $(\mathbf{k g})$ & $76.75 \pm 9.92$ & & -0.4434 & 0.2319 \\
\hline
\end{tabular}

\section{DISCUSSION}

There was negative association between the ratio of digits and depression and stress whereas positive association between the ratio of digits and anxiety. There was negative association between the ratio of digits and height and weight. Digit ratio is also called as 2D:4D ratio which is stable throughout the life. ${ }^{15}$ Lower digit ratio was observed in males when compared to females. ${ }^{16}$ The length of the second digit was slightly less than forth in case of males. ${ }^{17}$ In female population, low ratio of the digits indicates the features of autism and other disorders. ${ }^{18}$ Some studies reported presence of association is only between the ratio of digits ratio with the height and no association with any other anthropometric parameters. ${ }^{19}$ Other studies also mentioned presence of association between the ratio of digits and the demographic parameters. ${ }^{21}$ In contrast, other study that reported presence of association only between the ratio of digits and weight. ${ }^{20}$ Females experience more psychological problems than males. Hence, early diagnosis of these psychological changes is very beneficial as they allow us to offer effective management techniques. Earlier studies reported that higher the digit ratio, higher is the depression scores. ${ }^{22}$ This correlation of digit ratio with stress and other psychological disorders may be explained as the cortisol and testosterone levels are associated and the ratio of digits indicates the prenatal testosterone levels. ${ }^{24}$ The digit ratio is associated with the stress levels. ${ }^{23}$ It was reported that higher 2D:4D ratio has negative impact on health status. ${ }^{25}$ The Homeobox genes were reported to regulate the growth of the fingers. These genes were associated with the sex steroids. ${ }^{26}$ Earlier studies has not found correlation with male digit ratio. However, majority of the studies has observed correlation with females' digit ratio. Interestingly it was reported that in females the digit ratio was also associated with the Neuroticism. The present study included healthy female population and we have observed the correlation between the digit ratio with the anthropometric and the behavioural parameters. Less sample size may be the possible cause for non-significance of the correlation. This can be solved further conducting the study with more samples and also multiple centres.

\section{CONCLUSION}

There was a negative correlation between the digit ratio with depression, stress, height and weight parameters and has positive correlation with the anxiety. We recommend further detailed studies in this area for better understanding the association and to suggest the digit ratio as a simple and cost-effective measure for the stress levels.

\section{REFERENCES}

1. Barut C, Tan U, DoganA. Association of height and weight with second to fourth digit ratio (2D:4D) and sex differences. Percept Mot Skills. 2008; 106(2):627-32.

2. Hoekstra RA, Bartels M, Boomsma DI. Heritability of testosterone levels in 12-year-old twins and its relation to pubertal development. Twin Research and Human Genetics. 2006; 9(4):558-65.

3. Lucas A. Role of nutritional programming in determining adult morbidity. Archives of Disease in Childhood. 1994; 71(4):288-90. 
4. Fink B, Neavez N, Manning JT. Second to forth digit ratio, body mass index, waist-to-hip ratio and waist-tochestratio: Their relationships in heterosexual men and woman. Annals of Human Biology. 2003; 30(6):728-38.

5. Lutmaya S, Baron-Cohen S, Raggatt P, Knickmeyer R, Manning JT. 2nd to 4th Digit ratios, fetal testosterone and estradiol. Early Human Development. 2004; 77(1):23-8.

6. Manning J.T, Baron-Cohen. S. and Wheel wright. S. The 2nd to 4th digit ratio and autism. Developmental Medicine and Child Neurology. 2001; 43: 160-164.

7. Manning J. T., Scutt. D., Wilson. J., Lewis-Jones. D. I. The ratio of 2 nd to 4 th digit length: a predictor of sperm numbers and concentration of testosterone, leutinising hormone and estrogen. Human reproduction. 1998; 13(11), 3000-3004.

8. Wu. X., Yang. D., Chai. W., Jin. M, Zhou. X., Peng. L. and Zhao. Y. The Ratio of Second to Fourth Digit Length (2D:4D) and Coronary Artery Disease in a Han Chinese Population. International Journal of Medical Sciences 2013; 10(11):1584-1588.

9. Malkin C.J., Pugh P.J., Morris P.D., Asif. S., Jones. T.H. and Channer. K.S. (2010). Low serum testosterone and increased mortality in men with coronary heart disease. Heart. 2010; 96, 1821-1825.

10. Barut C, Tan U, DoganA. Association of height and weight with second to fourth digit ratio (2D:4D) and sex differences. Percept Mot Skills. 2008; 106(2):627-32.

11. Peeters MW, Van Aken K, ClaessensAL.The left hand second to fourth digit ratio (2D:4D) is not related to any physical fitness component in adolescent girls.PLoS One. 2013;8(4):e59766

12. M.P. VélezT.E. ArbuckleP. MonnierW.D. Fraser. Female digit length ratio (2D:4D) and time-to-pregnancy. 2016:31(9):2128-2134.

13. Richards AL, McGeachieJF.Patients' assessment of height and weight. Anaesthesia. 1994 Nov; 49(11):1008.

14. Lovibond, S.H. and Lovibond, P.f. Manual for the Depression anxiety Stress Scales.1995; (2nd Ed) Sydney: Psychology Foundation.

15. Lutchmaya, S., Baron-Cohen, S., Raggatt, P., Knickmeyer, R., and Manning, J. T. 2nd to 4th digit ratios, fetal testosteroneand estradiol. Early Human Development. 2004; 77(1):23-28.
16. Brown, W. M., Hines, M., Fane, B. A., and Breedlove, S. M. Masculinised finger length patterns in human males and females with congenital adrenal hyperplasia. Hormones and Behaviour. 2002; 42:380-386.

17. Burley, N. T., and Foster, V. S. Digit ratio varies withsex, egg order and strength of mate preference inzebra finches. Proceedings of the Royal Society B:Biological Sciences 2004;271, 239-244.

18. Esther I, DeBruin, Pieter F. A, DeboraHS,RobertF.Ferdinand autistic features in girls from apsychiatric sample are strongly associated with a low 2D:4D ratio Autism 2009;13:511-521.

19. Meera Jacob, Ramakrishna Avadhani, Bindhu Nair, Rani Nallathamby, Meril Ann Soman. Cross sectional study of second and fourth digit ratio with physical attributes in south indian population. Int J Anat Res 2015, Vol 3(2):1133-37.

20. Manning, J.T., Bundred, P.E., Newton, D.J., Flanagan,B.F., 2003. The second to fourth digit ratio andvariation in the androgen receptor gene. Evol. Hum.Behav. 2003; 24:399-405.

21. Tester.N,Campbell A. Sporting achievement; What is the contribution of digit ratio?.Journal of Personality. 2007; 75: 663-677.

22. Kerrie D.SmedleyKaylaJ.McKainDevonN.McKain. 2D:4D digit ratio predicts depression severity for females but not for males. Personality and Individual Differences. 2014; 70:136-139.

23. Portnoy J, Raine A, Glenn AL, Chen FR, Choy O, Granger DA. Digit ratio (2D:4D) moderates the relationship between cortisol reactivity and self-reported externalizing behavior in young adolescent males. Biol Psychol. 2015; 112: 94-106.

24. Kimberly A. Rapoza. Does life stress moderate/mediate the relationship between finger length ratio (2D4D), depression and physical health?Personality and Individual Differences. 2017; 113: 74-80.

25. Kondo, T., Zákány, J., Innis, J. W., and Duboule, D. Of fingers, toes and penises. Nature. 1997; 390:29

26. Geschwind, N., and Galaburda, A. M. Cerebral Lateralization. Cambridge, NA: MIT Press. 1987.

27. Bailey AA, Hurd PL. Finger length ratio (2D: 4D) correlates with physical aggression in men but not in women. Biological Psychology. 2005;68(3):215-22.

\section{Source of Support: None Declared} Conflict of Interest: None Declared 